\title{
As dinâmicas de poder na apropriação dos recursos hídricos: estudo de caso da bacia hidrográfica do rio Urussanga, SC
}

\author{
José Carlos Virtuoso ${ }^{1^{*}}$ (D), Carlyle Torres Bezerra de Menezes $^{2}$ (D), Viviani Kraieski Assunção (D) \\ ${ }^{1}$ Membro do Grupo de Pesquisa em Gestão de Recursos Hídricos e Restauração de Ambientes Alterados - Universidade \\ do Extremo Sul Catarinense (UNESC/CNPq), Av. Universitária, 1105 - Bairro Universitário- Criciúma-SC, 88806-000. \\ ${ }^{2}$ Programa de Pós-Graduação em Ciências Ambientais da. Universidade do Extremo Sul Catarinense (UNESC), Av. \\ Universitária, 1105 - Bairro Universitário- Criciúma-SC, 88806-000. \\ *Autor para correspondência: josecarlosvirtuoso@gmail.com
}

Recebido em 08 de setembro de 2020.

Aceito em 01 de dezembro de 2020.

Publicado em 31 de dezembro de 2020.

Resumo - Vivemos um contexto de estresse hídrico decorrente do modelo econômico hegemônico responsável por uma crise ambiental planetária sem precedentes, que vem causando a devastação dos ecossistemas e o desequilíbrio ecológico. Tal quadro pode ser constatado na Bacia Hidrográfica do rio Urussanga, Sul de Santa Catarina, onde atividades econômicas, como a mineração de carvão, promoveram severa degradação ambiental, contaminando solo, água e ar. Trata-se da bacia catarinense de menor área, porém com passivos ambientais ainda sem intervenção. Diante desse cenário, o presente trabalho buscou analisar as dinâmicas de poder determinantes na apropriação dos recursos hídricos nesse território. Para tanto, realizou-se pesquisa de abordagem qualitativa, nas modalidades bibliográfica, documental, de campo e estudo de caso, utilizando-se instrumento de análise com enfoque na apropriação de recursos comuns. Como resultados, constatou-se sobreposição de poder do setor econômico em relação ao interesse coletivo, como na gestão da água, cuja atuação de um setor alinha-se aos segmentos políticos, identificando-se fatores que evidenciam assimetria nos espaços de tomada de decisão. Nesse contexto, o carbonífero se destaca, utilizando estratégias como financiamento de campanhas políticas para se manter, mesmo diante de indicadores de insustentabilidade. Concomitantemente, os instrumentos legais de tutela da água mostram-se insuficientes para evitar a sua poluição.

Palavras-chave: Água; Degradação Ambiental; Sobreposição de Poder; Estresse Hídrico.

\section{The dynamics of power in the appropriation of hydric resources: case study of the drainage basin of the Urussanga river, SC}

\begin{abstract}
We live in a context of hydric stress resulting from the hegemonic economic model, responsible for an unprecedented global environmental crisis, which has been causing the devastation of ecosystems and ecological imbalance. Such a picture can be seen in the Drainage Basin of the Urussanga River, in the South of Santa Catarina, where economic activities, such as coal mining, have promoted severe environmental degradation, contaminating soil, water, and air. This is the smallest drainage basin in Santa Catarina, but with environmental liabilities that have yet to receive intervention. In view of this scenario, the present study intended to analyze the power dynamics that determine the appropriation of hydric resources in this territory. To this end, a qualitative research
\end{abstract}


was carried out, in the bibliographic, documentary and case study modalities, using an analysis instrument with a focus on the appropriation of common resources. As a result, it is possible to see a superposition of power in the economic sector in relation to the collective interest, as in hydric management, the performance of which, as a sector, is aligned with political segments, identifying factors that show asymmetry in the decision-making spaces. In this context, the coal industry stands out, using strategies such as financing political campaigns to preserve itself, even if confronted with unsustainability indicators. Concomitantly, the legal instruments of hydric protection are insufficient to prevent the pollution.

Keywords: Water; Environmental Degradation; Superposition of Power; Hydric Stress.

\section{Las dinámicas de poder en la apropiación de los recursos hídricos: estudio de caso de la cuenca hidrográfica del rio Urussanga, SC}

Resumen - Vivimos un contexto de estrés hídrico causado por el modelo económico hegemónico responsable de una crisis ambiental planetaria sin precedentes, que ha resultado en la devastación de los ecosistemas y el desequilibrio ecológico. Tal cuadro puede ser comprobado en la Cuenca Hidrográfica del río Urussanga, Sur de Santa Catarina, donde actividades económicas, como la minería de carbón, fomentaron severa degradación ambiental, contaminando suelo, agua y aire. Se trata de la cuenca más pequeña de Santa Catarina, pero con pasivos ambientales aún sin intervención. Ante ese escenario, el presente trabajo buscó analizar las dinámicas de poder determinantes en la apropiación de los recursos hídricos en este territorio. Para ello, se realizó un estudio de abordaje cuantitativo, en las modalidades bibliográfica, documental, de campo y estudio de caso, utilizando instrumento de análisis con enfoque en la apropiación de recursos comunes. Como resultados, se constató superposición de poder del sector económico en relación al interés colectivo, como en la gestión del agua, cuya actuación de un sector se ajusta a los segmentos políticos, identificando factores que evidencian asimetría en los espacios de toma de decisión. En este contexto, el sector del carbón se destaca, utilizando estrategias como financiación de campañas políticas para mantenerse, incluso ante indicadores de insustentabilidad. Concomitantemente, los instrumentos legales de tutela de agua se muestran insuficientes para evitar su contaminación.

Palabras-clave: Agua; Degradación Ambiental; Superposición de Poder; Estrés Hídrico.

\section{Introdução}

A apropriação e uso dos recursos naturais do planeta de forma predatória, ao longo dos últimos dois séculos e meio, provocou uma crise ambiental sem precedentes na história. A poluição do solo, do ar, das águas e a devastação das florestas representam uma combinação adversa, alterando as condições climáticas no planeta Terra e expondo as diversas formas de vida ao risco de extinção (Melo 2006; Porto e Porto 2017; Marques 2016). Nesse contexto, dentre tantas consequências negativas, de um modo particular, destaca-se a redução drástica da disponibilidade hídrica em todos os continentes, caracterizando uma crise global em relação ao acesso à água.

Associado ao problema hídrico reportado como agravante, o aumento populacional no planeta, já superior a sete bilhões de pessoas, implica a ampliação exponencial do consumo de água, acompanhada de maior dificuldade de seu acesso, em face dos múltiplos impactos decorrentes desse crescimento demográfico. Além disso, tem-se a poluição como uma das principais causas do 
problema, com a contaminação dos rios pelo lançamento de resíduos das mais diversas naturezas, com agravamento devido às mudanças climáticas (Bicudo et al. 2010; Jacobi et al. 2015; Jacobi e Grandisoli 2017; Marques 2016).

Há muito tempo especialistas vêm alertando sobre o uso insustentável dos recursos hídricos e suas inevitáveis consequências. O cenário atual, nestas duas primeiras décadas do terceiro milênio, já materializa o que se pode chamar de "crise da água", considerando-se as situações verificadas globalmente (Jacobi et al. 2015; Jacobi e Grandisol 2017; Marques 2017). Tal processo coloca a água como "elemento-chave" na questão ambiental: a sua ausência, ou contaminação, leva à redução dos espaços de vida e ocasiona, além de imensos custos humanos, uma perda global de produtividade social". (Dowbor 2005, p. 27).

O quadro global na atualidade, portanto, representa uma preocupação real, considerando números indicados por organismos internacionais, como a ONU, por meio do IPCC (Intergovernmental Panel on Climate Change), dando conta de que $80 \%$ da população mundial já estão sob ameaça de indisponibilidade hídrica. Ao mesmo tempo, metade deste contingente não demorará a conviver em meio ao estresse hídrico (Jacobi et al. 2015; Jacobi e Grandisoli 2017). Diante desse cenário, a dificuldade de acesso ou a inacessibilidade vem se tornando uma realidade concreta, pois, segundo a OMS e o UNICEF (2017), três em cada 10 pessoas não têm acesso a água potável, o que representa um montante de 2,1 bilhões, ou quase um terço da população planetária.

O Brasil também está inserido neste quadro problemático. Detentor do maior depositário mundial de água doce (Augusto et al. 2012), o país viu sua preocupação hídrica histórica relacionada ao Nordeste - região com tendência de agravamento (Getirana 2016), estender-se ao Sudeste (Matsuki e Sinimbú 2018). Um longo período de estiagem marcou o início da segunda década do século XXI, entre 2013 e 2014, quase levando ao colapso o Sistema Cantareira, responsável pelo abastecimento de milhões de pessoas na região metropolitana de São Paulo. Situação essa relacionada igualmente ao mau gerenciamento dos recursos hídricos (Jacobi et al. 2015; Tundisi e Tundisi 2015).

Seguindo a tendência brasileira, Santa Catarina atingiu igualmente um nível preocupante no tocante ao seu quadro hídrico, conforme o diagnóstico do Plano Estadual de Recursos Hídricos (PERH), apresentado em 2018. Segundo o estudo, praticamente todas as dez regiões hidrográficas (RH) catarinenses estão em situação delicada, considerando os balanços quali e quantitativo (Santa Catarina 2018). Entre elas, duas apresentam uma situação ainda mais grave, a RH6, no Norte do Estado, formada pelas bacias dos rios Cubatão do Norte, Cachoeira e Itapocu, e a RH10, formada pelas bacias dos rios Araranguá e Urussanga, na região Sul. Ambas apresentam maior criticidade, considerando as vazões de retirada dos setores usuários em razão das altas demandas de uso da água, sobretudo a RH10, cuja necessidade de captação é maior do que a disponibilidade hídrica, no caso da rizicultura irrigada (Santa Catarina 2018).

As duas regiões hidrográficas catarinense mais problemáticas têm em comum um histórico de degradação, em razão do modelo econômico predatório, responsável pela poluição dos mananciais de água. Particularmente a RH10, impactada há muitas décadas pela extração e beneficiamento de carvão mineral. A mesma atividade que gerou riquezas, deixou importante passivo ambiental, com o comprometimento do solo e das águas superficiais e subterrâneas, dentre outros tantos impactos. Por consequência, essa foi classificada, em 1980, como a $14^{\text {a }}$ área crítica nacional referente à 
necessidade de controle da poluição e conservação da qualidade ambiental (Scheibe 2002; Corrêa 2004; Milioli 2009; Carola 2010; Castilhos e Fernandes 2011).

Não obstante o estabelecimento de mecanismos legais à gestão hídrica, como em outras várias esferas de interesse socioambiental, as políticas voltadas à preservação tanto da água como de outros recursos naturais têm sido ineficazes, uma vez que os processos de degradação não cessaram. Considerando, portanto, tal contexto, o presente trabalho tem como objetivo analisar as dinâmicas de poder na apropriação da água no território da bacia hidrográfica do rio Urussanga, identificando as limitações que impossibilitam o estabelecimento de uma governança efetiva à gestão hídrica no seu território, conforme preconiza a Política Nacional de Recursos Hídricos (PNRH), Lei 9.433/1997. Trata-se da bacia mais crítica do estado, em relação à disponibilidade hídrica, em quantidade e qualidade, que já passa por um processo iminente de colapso hídrico.

O histórico de degradação transcorrido no território da bacia hidrográfica em estudo teve como desfecho o comprometimento de boa parte dos seus mananciais hídricos. Tal contexto é dimensionado nesse artigo, considerando os seus múltiplos aspectos, dentre eles a atuação dos vários atores envolvidos nas dinâmicas de apropriação e gestão da água local e as instâncias de poder envolvidas nas tomadas de decisão sobre a apropriação dos recursos hídricos.

\section{Material e métodos}

\section{Área de estudo}

A bacia hidrográfica do rio Urussanga (Figura 1) localiza-se entre as latitudes $28^{\circ} 26^{\prime}$ S e $28^{\circ} 49^{\prime}$ S e longitudes $49^{\circ} 25^{\prime} \mathrm{W}$ e $4^{\circ} 06^{\prime} \mathrm{W}$ (Back, 2009), estando inserida na $10^{\text {a }}$ Região Hidrográfica de Santa Catarina (RH10). Situa-se entre as bacias do rio Araranguá, ao sul, e Tubarão, ao norte, correspondendo a uma área de $675,75 \mathrm{~km}^{2}$, abrangendo 10 municípios: Cocal do Sul, Morro da Fumaça, Içara, Urussanga, Pedras Grandes, Treze de Maio, Sangão, Jaguaruna, Criciúma e Balneário Rincão. Suas características a colocam como a menor entre as três bacias da região e a menor do Estado, correspondendo a 0,70\% do território catarinense (Galatto et al. 2015). O rio principal possui 43,05 km de extensão, chegando à foz, na Barra do Torneiro, município de Balneário Rincão. 
Figura 1. Localização espacial da bacia do rio Urussanga.
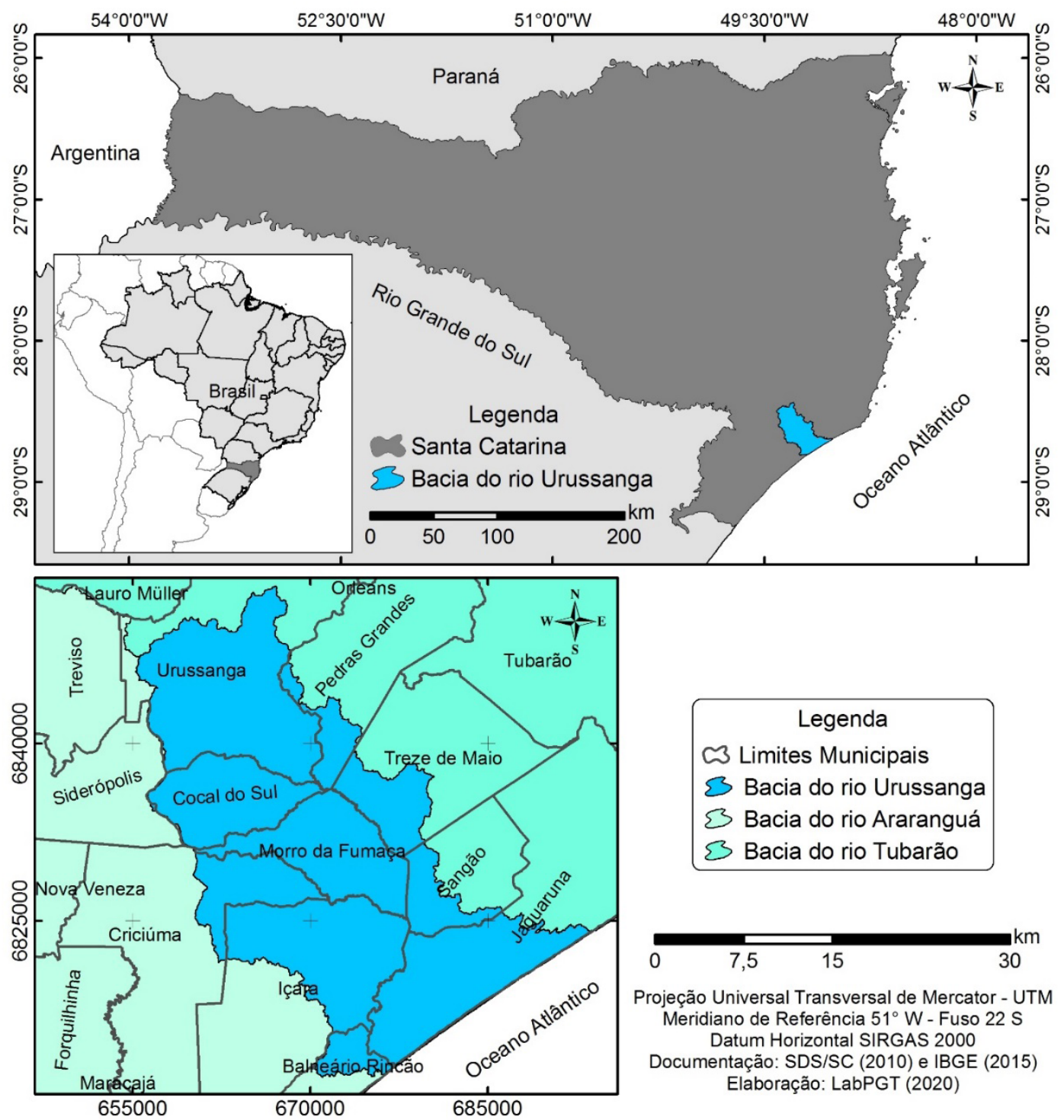

Projeção Universal Transversal de Mercator - UTM Meridiano de Referência $51^{\circ} \mathrm{W}$ - Fuso $22 \mathrm{~S}$ Datum Horizontal SIRGAS 2000 Documentação: SDS/SC (2010) e IBGE (2015) Elaboração: LabPGT (2020)

Fonte: LabPGT/UNESC (2019).

Formado a partir da confluência dos rios Maior e Carvão, o rio Urussanga tem suas nascentes situadas "nos compartimentos de relevo das Serras do Leste Catarinense e nos Contrafortes da Serra Geral, respectivamente" (CBHRU 2010, p. 3). Essas estão localizadas "em cotas altimétricas de cerca de 360 metros e, a sudoeste e nos morros a nordeste, nas Serras do Leste Catarinense, a uma altitude aproximada de 500 metros" (CBHRU 2010, p. 3). O rio Urussanga, em sua margem direita, tem como afluentes os rios América, Caeté, Cocal, Ronco D’Água, Linha Torrens, Linha Anta, Três Ribeirões e Lagoa da Urussanga Velha e, em sua margem esquerda, os rios Barro Vermelho, Ribeirão da Areia e Vargedo.

A população da bacia hidrográfica do rio Urussanga é de aproximadamente 120 mil pessoas. Dos 10 municípios que a compõem, apenas Cocal do Sul e Morro da Fumaça estão inseridos totalmente em sua área de abrangência, somando juntos pouco mais de 31 mil habitantes. Já Içara tem $49,5 \%$ de sua área dentro da bacia, enquanto Urussanga chega a $61 \%$, estando as sedes de ambos os municípios situadas dentro da bacia (Adami e Cunha 2014). 


\section{Características da pesquisa}

Este trabalho resulta de pesquisa com abordagem qualitativa, caracterizando-se ainda como um estudo de caso, documental e participante, levando-se em conta a relação estreita de um dos autores com o objeto pesquisado, com participação do processo de gestão do comitê de bacia hidrográfica do rio Urussanga.

A pesquisa documental deu-se por meio do levantamento de dados em documentos (eletrônicos ou impressos), durante todo o período de 2015 a 2018. No âmbito do comitê de bacia hidrográfica, foram analisados conteúdos referentes a conflitos pelo uso de água e questões políticas de tensionamento nas dinâmicas do órgão colegiado, entre outros aspectos, que puderam ser identificados também durante a realização das entrevistas com os atores.

Os registros sobre as dinâmicas do comitê em tomadas de decisão, bem como de outros fatos ocorridos relacionados ao problema da pesquisa (nas diferentes escalas), foram identificados a partir das atas e registros informativos noticiosos disponíveis no acervo do órgão e em sítios eletrônicos. Alguns documentos oficiais foram acessados nos seus arquivos, em sua sede, no município de Urussanga, com o apoio da sua consultora técnica. Conteúdos de atas relativas a essa questão foram acessados no sítio eletrônico do comitê. Da mesma forma, informações referentes aos movimentos dos diversos setores da bacia foram obtidas por meio sítios eletrônicos, considerando que a maior parte dessas mobilizações ainda não se encontra registrada em publicações acadêmicas, mas em espaços jornalísticos digitais.

A entrevista semiestruturada foi igualmente utilizada para a coleta de dados junto a atores atuantes no território da bacia hidrográfica, por ser considerada como importante ferramenta à coleta de dados, ao permitir o acesso a "[...] informações e elementos de reflexão muito ricos e matizados" (Quivy e Campenhoudt 2005, p. 22). Tal expediente abrangeu integrantes do comitê (seis membros, representantes da população da bacia, usuários e órgãos governamentais), agentes econômicos (três representantes, um de entidade representativa e outros dois empresários), agentes do segmento político (dois políticos, com cargos eletivos, um vereador e outro prefeito, de um total de quatro representantes previstos, incluindo um deputado estadual e um federal, os quais não confirmaram participação até o final do trabalho) e do segmento acadêmico (três pesquisadores que abordam a questão hídrica em suas atividades).

Ao todo 14 pessoas foram entrevistadas, entre os meses de julho e setembro de 2018. Todas as conversas foram registradas por meio de gravador de áudio, mediante autorização de cada participante, ao assinar o Termo de Consentimento Livre e Esclarecido (TCLE), em cumprimento à Resolução no 466/2012 do CNS - Conselho Nacional de Saúde. O projeto de pesquisa foi aprovado junto ao Comitê de Ética em Pesquisa da Universidade do Extremo Sul catarinense (UNESC), sob o Parecer no 2.399.900/2017.

Os registros no âmbito da pesquisa participante estão diretamente associados ao uso do diário de observação de campo. As informações obtidas pelo pesquisador foram registradas ao longo de sua atuação durante quatro anos em que presidiu o comitê, em diversos eventos, tanto ordinários como extraordinários (reuniões técnicas, políticas, assembleias, formações, etc.), além dos momentos de interação com os atores envolvidos no processo, em âmbito local, regional, estadual e até nacional. 


\section{Instrumento para a análise de dados}

A gestão de recursos naturais, como os hídricos, remete a um contexto complexo, composto por múltiplos atores e instituições, em jogos de interesses igualmente diferenciados, que caracterizam as dinâmicas do território na apropriação da água. Assim, optou-se pela utilização de um modelo analítico afeito ao alto grau de complexidade que o problema engendra, recorrendo-se às quatro macrovariáveis de Oakerson (1992). Sua aplicação permitiu a identificação dos significados por trás das articulações envolvendo os recursos hídricos na área abrangida pelo estudo. São elas: os atributos físicos e tecnológicos do recurso; as regras de interação dos atores envolvidos na gestão, a arena de ação na qual ocorrem as interações entre os envolvidos e os resultados e consequências da gestão.

As quatro macrovariáveis constituem, de modo articulado, um instrumento que contribui à compreensão e prospecção de possibilidades alternativas futuras na gestão dos recursos em caráter de bens comuns, como é o caso da água. Embasados em Hess e Ostrom (2007) e Oakerson (1992), essas são brevemente descritas a seguir, estando representadas subsequentemente na Figura 2:

Atributos físicos e tecnológicos: os recursos comuns apresentam limites de uso, conforme a sua natureza, dependendo de onde estão localizados, a sua quantidade e abundância etc. Preponderantemente, tem-se como principal atributo, aqui, a água, além dos elementos com os quais mantém relação de interdependência, como os geológicos, geomorfológicos, clima e cobertura vegetal. Diante destes aspectos, a tecnologia acaba sendo determinante para a forma como se faz o manejo dos recursos e os aspectos inter-relacionados a estes.

Arranjos institucionais: as dinâmicas de apropriação e uso dos recursos comuns engendram regramentos para este fim, respaldando as escolhas individuais e coletivas. Tais regras devem contribuir para que se estabeleça uma relação de equilíbrio e os recursos se mantenham em padrão de disponibilidade em regime de propriedade comum.

Os padrões de interação: As interações nos processos de gestão dos recursos comuns envolvendo os atores - agentes políticos, econômicos e sociedade - dão-se num espaço em que são tomadas as decisões. Nem sempre aqui se tem a observância dos regramentos. Assim, no âmbito de uma arena de ação, ocorre a experiência das escolhas, com a participação de segmentos, em regime cooperativo ou não, bem como as consequências destas, as quais podem ser positivas ou negativas.

Os resultados e consequências: As interações nos processos de apropriação dos recursos comuns apresentam inter-relações entre as três primeiras macrovariáveis, sendo a terceira (os padrões de interação) a responsável por gerar respostas, que são os resultados ou consequências.

Figura 2. Modelo de análise de Oakerson (1992).

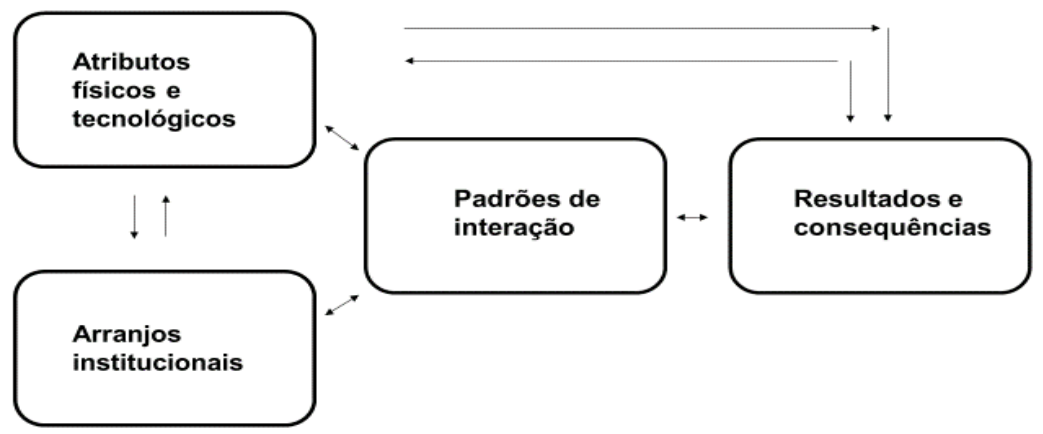

Fonte: Hess e Ostrom (2007) (adaptado) e Oakerson (1992). 
Em razão do grande volume de dados gerados a partir das quatro macrovariáveis no contexto da pesquisa, fez-se opção por se trabalhar nesse artigo duas das quatro macrovariáveis, "Os padrões de interação" e os "resultados e consequências", que delineiam as dinâmicas socioambientais do território estudado. Esses compreendem os jogos de atores "na arena de ação" e suas implicações sobre o território da bacia hidrográfica do rio Urussanga.

\section{Resultados e discussão}

\section{A atuação dos segmentos econômicos}

Os atores dos segmentos econômicos representam uma participação decisiva na construção do território, o qual resulta das ações combinadas destes (Cazella et al. 2009). Logo, dentro dessa lógica, o território da Bacia Hidrográfica do rio Urussanga foi tecido historicamente desde a colonização por imigrantes europeus, principalmente italianos, a partir da segunda metade do século XIX, durante ciclos econômicos. Com o transcorrer das várias décadas, esses se sucederam, a começar pela predominância inicial da agricultura, caracterizada por várias atividades afins, incluindo a produção agrícola alimentar e a vitivinicultura. Subsequentemente, iniciou-se a mineração de carvão e de outros minerais, além de setores como os de serviços e revestimentos cerâmicos, que estão organizados por meio de associações comerciais e mistas (Butzke 2014).

Ao longo do tempo, os setores econômicos atuantes no território da bacia têm-se guiado por processos de mobilização ocorridos na região Sul Catarinense, propondo-se a estabelecer o planejamento e promoção de um desenvolvimento regional integrado, dentre outros intentos, como um dos seus principais focos, conforme têm sinalizado. As articulações, para este fim, têm ocorrido principalmente nas últimas duas décadas, com eventos que se repetem com certa periodicidade, envolvendo representantes dos vários municípios das três microrregiões - AMREC (onde se insere o território em estudo) AMESC (Associação de Municípios do Extremo Sul Catarinense) e AMUREL (Associação dos Municípios da Região de Laguna). Em pauta, a discussão de estratégias ao fortalecimento econômico regional, de forma mais abrangente, entre elas o aumento da representatividade política regional e a melhoria da infraestrutura como suporte ao desenvolvimento econômico regional.

Em boa parte das mobilizações a que se tem registro, constata-se a existência de objetivos difusos, ou seja, não atinentes a nenhum setor em especial. Um exemplo disso remete à década de 1990, com uma mobilização envolvendo diversos setores pela construção de uma barragem na região, com o propósito de solucionar o problema de escassez hídrica, em decorrência da poluição química dos mananciais hídricos da região, sobretudo pelos metais pesados da mineração, dentre outras fontes (Casan 2006). Temia-se por um possível colapso no abastecimento de água, o que gerou forte apelo intersetorial, sendo criado inclusive, em 1997, o Fórum de Desenvolvimento Regional, estabelecendo como uma das prioridades a viabilização da barragem do Rio São Bento. A obra, ilustrada na Figura 3, foi construída no município de Siderópolis, para o abastecimento de aproximadamente 300 mil pessoas, dos municípios de Criciúma, Nova Veneza, Içara, Morro da Fumaça, Maracajá, Meleiro e Forquilhinha, com um tempo de vida útil de 30 anos (Casan 2006). 
Figura 3. Lago artificial formado pela barragem do Rio São Bento.

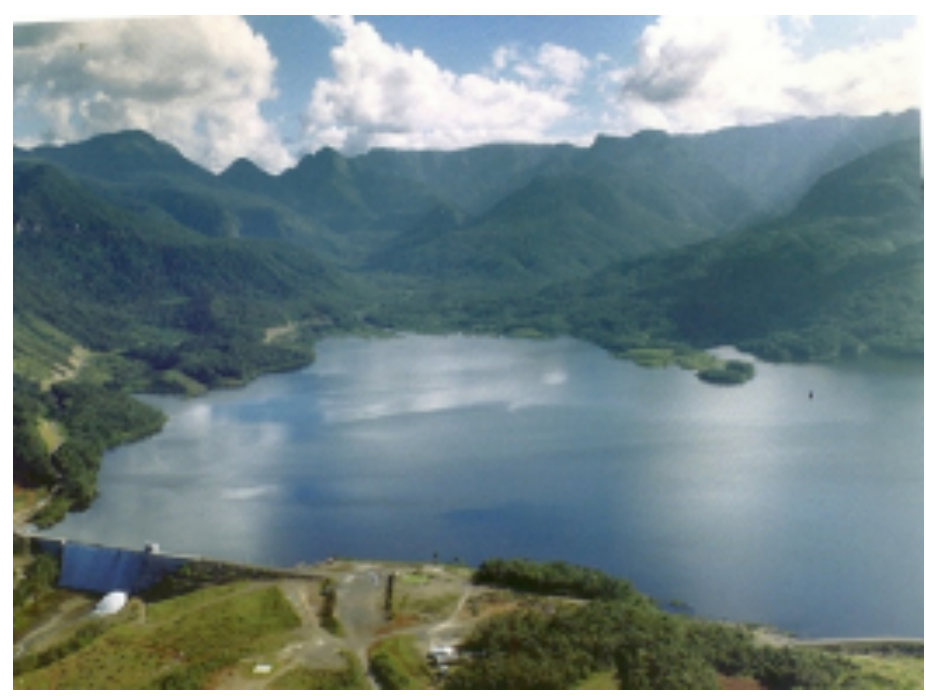

Fonte: Casan (2006).

Contrastando com o contexto de causas coletivas de interesse difuso, no entanto, dois setores da indústria, o cerâmico e, principalmente, o carbonífero, destacam-se pelo poder de mobilização em prol de seus próprios projetos. De um modo particular, ainda nos anos 1990, os ceramistas, por meio da sua entidade representativa, o Sindicato das Indústrias de Revestimentos Cerâmicos de Santa Catarina (Sindiceram), articularam-se com agentes econômicos e políticos regionais e do governo do Estado para a implantação de um gasoduto para o transporte de gás natural da Bolívia como alternativa energética ao setor. Deste modo, o gasoduto Brasil-Bolívia, originalmente previsto para ser concluído no Estado de São Paulo, foi estendido até o Sul catarinense, para substituir o GLP (gás liquefeito de petróleo) na queima das peças cerâmicas com redução de custos. (Silva e Garcia 2005).

A indústria carbonífera, por sua vez, apresenta um certo establishment, por sua capacidade de mobilização em âmbito econômico e político muito acima dos demais setores, considerando a teia de entidades que lhe dão suporte, consolidada ao longo de uma jornada centenária de atuação na região. Sua base inicial de sustentação em nível local e regional é o Sindicato da Indústria de Extração do Estado de Santa Catarina (Siecesc), além de representação nacional em nível de associação e sindicato patronal. Continua bastante evidente o respaldo dado ao setor por parte do segmento político, mesmo em período de baixa do carvão, em razão do movimento global defensor da substituição dos combustíveis fósseis por tecnologias de base renovável (Butzke 2014). Tal fato decorre da sua antiga base histórica, na qual o complexo carbonífero constituiu-se "[...] a partir de uma ligação político-estrutural entre a esfera pública e privada” (Teixeira 1996, p. 16).

A relação entre agentes políticos catarinenses e as carboníferas pode ser constatada mediante doações das empresas em campanhas eleitorais. No período entre 2002 e 2014, por exemplo, muitos candidatos às eleições majoritárias e proporcionais, nos âmbitos municipal, estadual e federal, receberam doações, conforme os registros acusados no sítio eletrônico do Tribunal Superior Eleitoral (TSE). O valor investido ultrapassou os R \$ 6 milhões, beneficiando políticos dos diversos partidos, demonstrando a estratégia agressiva adotada pelos mineradores com objetivo de obter maior força política nas instâncias de decisão, sobretudo referente à matriz energética no país. 
O apoio financeiro a campanhas eleitorais possibilitou ao segmento carbonífero arranjos que lhes propiciaram representação política institucionalizada no âmbito legislativo, de influência regional, estadual e nacional. Em nível estadual, foi criada a Frente Parlamentar Catarinense em Defesa do Carvão Mineral, com a Frente Parlamentar Mista em Defesa do Carvão Mineral atuando no Congresso Nacional (Butzke 2014). Concomitantemente, o setor investiu em estratégias para a melhoria da sua imagem, buscando contrapor os efeitos negativos da Ação Civil Pública, chamada ACP do Carvão - processo 93.8000533-4), que obriga as empresas carboníferas a realizar projetos de recuperação ambiental na região e a consequente remediação do problema dos passivos ambientais. Com esse fim, patrocinou o futebol profissional, colocando sua marca no time da cidade, Criciúma Esporte Clube, durante uma década. E se inseriu nos mais diversos órgãos colegiados, como a Associação Empresarial de Criciúma (ACIC), na qual exerce forte poder de influência, ocupado funções de comando.

A atuação no âmbito político rendeu ao setor carbonífero resultados positivos como captação de recursos públicos para a execução de seus projetos como o voltado ao desenvolvimento de tecnologia de captura de $\mathrm{CO}_{2}$ (dióxido de carbono) e gaseificação de carvão. Foram aproximadamente $\mathrm{R}$ \$,4 milhões, oriundos da Fundação de Apoio à Pesquisa Científica e Tecnológica do Estado de Santa Catarina - FAPESC (R\$ 3,8 milhões), a Centrais Elétricas Brasileiras - Eletrobras, com R\$ 1,5 milhão, e Financiadora de Estudos e Projetos - FINEP, outros R\$2,1 milhões (FAPESC 2010).

Conforme se pôde depreender, a partir da análise de registros das atuações dos segmentos econômicos, a mineração de carvão sobressai-se de forma destacada, em suas articulações na defesa de seus interesses. Da mesma forma, fica evidenciado que os agentes econômicos, com influência direta ou indireta nas dinâmicas territoriais da bacia do rio Urussanga, não têm os recursos hídricos como prioridade em sua agenda.

\section{A atuação dos segmentos políticos}

Os segmentos políticos, a exemplo dos econômicos, configuram-se como um conjunto de atores de participação decisiva nas tomadas de decisão envolvendo os processos de construção do território. Inserem-se nesse contexto órgãos públicos e seus representantes vinculados a governos executivos, órgãos de fiscalização, órgãos legislativos e judiciários. Sua participação em processos desencadeados na bacia hidrográfica do rio Urussanga está alinhada, em grande parte, à agenda econômica.

No tocante aos atores políticos atuantes de forma direta na bacia, importa trazer à tona a mobilização de prefeitos, vereadores de municípios da Amrec situados dentro da bacia, no início dos anos 2000, pelo desassoreamento do rio Urussanga, com o apoio de deputados representantes da região. Além da contaminação hídrica, o leito do rio apresentava situação delicada em função do assoreamento, por conta da presença de sedimentos oriundos da mineração de carvão e areia, sendo recorrentes inundações em áreas urbanas, como no município de Morro da Fumaça (Galatto et al. 2015). Em decorrência dessa iniciativa foi a criado, em 2006, o Comitê de Gerenciamento da Bacia Hidrográfica do Rio Urussanga (CBHRU), por meio do Decreto Estadual no 4.934, seguindo diretrizes das Leis Estadual no 9.748/1994 e Federal no 9.433/1997.

A mobilização em torno dos problemas do rio Urussanga teve sequência ao longo de quase uma década, com uma série de iniciativas. Reuniões, audiências públicas e outras ações foram 
realizadas, culminando com a elaboração de um projeto de desassoreamento do rio, orçado em R\$ 120 milhões, ao qual a licença ambiental chegou a ser requerida junto à Fundação de Meio Ambiente de Santa Catarina (FATMA), hoje Instituto de Meio Ambiente (IMA). No entanto, sem a garantia de recursos para as obras, o processo de licenciamento ambiental não havia evoluído até o início de 2020.

O segmento político da bacia também esteve envolvido em processo polêmico relacionado à alteração de legislação municipal para beneficiar a implantação de uma mina de carvão no município de Içara, em 2011. O episódio ficou conhecido como “escândalo das cédulas", em sessão quando ocorreu votação com cédulas marcadas para derrubar veto do prefeito contra a extinção de uma Área de Preservação Permanente (APP). Três vereadores, um agente econômico vinculado à cooperativa de eletrificação local e a mineradora Rio Deserto foram condenados pelo Tribunal de Justiça de Santa Catarina (TJSC). Os sentenciados recorreram da decisão, com o processo ainda sem decisão definitiva da Justiça.

As dinâmicas da bacia também são direcionadas a partir da atuação dos órgãos fiscalizadores, que incide diretamente sobre os recursos hídricos, para a sua preservação ou deterioração, conforme o grau de efetividade. Nesse sentido, destaca-se o desempenho do IMA no território da bacia, ressaltado, sobretudo, em alguns conflitos socioambientais por conta do seu papel de licenciador. Um deles é o caso da localidade de Rio Maior, em Urussanga, onde a Setep Construções extrai Diabásio e promove britagem e usinagem de asfalto. Por meio de sua associação de moradores, Acrima, a população local resistiu à implantação do empreendimento e, apesar de estar na área de abrangência de uma área de proteção ambiental (APA), criada pelo município, não conseguiu impedir a abertura da atividade. No processo, conforme Nascimento e Bursztyn (2012, p. 179), houve a concessão de licenças irregulares ao mesmo tempo em que o órgão mostrou-se "muito mais favorável à empresa mineradora do que à comunidade".

A atuação do IMA foi igualmente objeto de críticas envolvendo outro conflito socioambiental, tendo como atores uma comunidade de agricultores e uma mineradora de carvão, na comunidade de Santa Cruz e adjacências, em Içara. Sua credibilidade foi questionada, levando-se em conta licenças que teriam sido concedidas de forma irregular no processo de implantação da mina de carvão na localidade de Santa Cruz. Situação que evidencia a posição favorável dos segmentos políticos e econômicos da região em relação à atividade minerária (Nascimento e Bursztyn 2010).

\section{A atuação da sociedade civil}

A participação da sociedade civil em processos de mobilização na defesa de interesses comuns relacionados aos recursos hídricos, no território da bacia, tem sido restrita a ações de grupos específicos, com alguma exceção. Sobretudo, em situações de conflito. De um modo geral, não se verificam fatos que demonstrem a articulação de um conjunto maior da população relacionada aos problemas da água. Portanto, é no âmbito de episódios envolvendo comunidades específicas que se constatam iniciativas em defesa de questões coletivas referentes à temática socioambiental, em processos conflituosos relativos a atividades econômicas e seus impactos negativos em determinada localidade.

No contexto em questão enquadra-se o conflito na comunidade de Rio Carvão, Urussanga, onde a população denuncia há vários anos a degradação promovida por duas coquerias, com impactos na 
água, no solo e no ar (Echevenguá 2010; Moretti 2010). Os moradores reclamam principalmente do pó preto (material particulado) que é emitido durante a atividade, que transforma carvão mineral em coque, insumo para a produção de aço. Por conta dos impactos, a empresas tiveram que assinar, em 2006, um Termo de Ajuste de Conduta (TAC) com o Ministério Público Federal (MPF), Fatma/ IMA e DNPM, mas não cumpriram os compromissos assumidos de minimização do problema (Echevenguá 2010).

Outra mobilização de caráter emblemático é o referido caso de Rio Maior, em Urussanga. O conflito envolvia a exploração de diabásio na localidade, dentre outras atividades, com impactos que tiveram como desdobramento uma ação civil pública impetrada pelo MPF e a Acrima. Um dos grandes protagonistas do processo foi o ente representativo da população afetada, pelo nível de organização comunitária, fazendo com que algumas conquistas importantes fossem asseguradas ao adotar um comportamento proativo, como o monitoramento das ações da empresa e a redução e controle de impactos (Nascimento e Bursztyn 2012).

Todos os eventos citados têm um significado importante no âmbito da mobilização social em defesa do meio ambiente, com relação direta à água. No entanto, o episódio de maior impacto na região, principalmente, no âmbito do território da bacia do Urussanga, foi o da resistência de agricultores das localidades de Santa Cruz, Espigão, Esperança e entornos, em Içara, à implantação de uma mina de carvão. O movimento iniciou em 2003, com a comunidade articulando-se para impedir a instalação do empreendimento. Foram realizados vários atos, incluindo reuniões com lideranças políticas do município, dos órgãos ambientais e setores econômicos contrários à mineração (Schneider et al. 2018).

A mobilização social de Içara, originalmente composta por agricultores (Santos e Santos 2010), acabou se ampliando, a partir de 2008, com a adesão de mais de 70 entidades do município, que passaram a atuar ativamente nas ações de resistência. Entre as entidades, figuravam a Câmara de Dirigentes Lojistas de Içara (CDL), a Associação Comercial e Industrial de Içara (ACII) e a União das Associações Comunitárias de Içara (UACI). Fortalecida, passou-se a chamar de Movimento Içarense pela Vida (MIV), ganhando robustez e representatividade diante dos pleitos que defendia, em âmbito regional (Nascimento e Bursztyn 2010).

A questão ambiental na região, incluindo o território da bacia hidrográfica do rio Urussanga, tem também recebido especial atenção por parte de pesquisadores da Universidade do Extremo Sul Catarinense (Unesc). Em particular, o grupo Memória e Cultura do Carvão em Santa Catarina, que atuou durante mais de uma década, sendo referência ao realizar estudos sobre o histórico da mineração de carvão no Estado, trazendo à tona as suas nuances socioeconômicas e, sobretudo, ambientais. (Butzke 2014).

\section{Resultados e consequências das decisões nos usos da água}

Os resultados e consequências das decisões acerca dos usos dos recursos hídricos na bacia do rio Urussanga compreendem a conjugação dos diversos fatores presentes no cotidiano do seu território. Esses representam um elemento importante nesse trabalho, como síntese dos processos decorrentes das dinâmicas envolvendo os diversos atores na apropriação da água, na qualidade de recurso comum. No caso da área em estudo, seria desejável que o cenário dimensionado a partir da análise de um quadro complexo pudesse ser mais favorável. No entanto, a realidade auferida suscita 
grande preocupação, em face da sua gravidade não só pelos problemas socioambientais imbricados no processo, em si, como também pelas fragilidades nos arranjos de governança que poderiam contribuir à sua superação.

Tem-se no território da bacia hidrográfica um quadro bastante delicado em relação à disponibilidade da água em quantidade e qualidade, em decorrência do modelo de manejo adotado na região, com contaminação hídrica e outros agravantes, conforme já aludido. Panorama que ficou bem caracterizado no prognóstico da evolução do balanço hídrico de Santa Catarina do PERH. A conjectura contempla uma sequência de anos, incluindo 2019, 2023 e 2027, considerando a projeção de crescimento da necessidade de água para diferentes usos, compondo um cenário tendencial. Entre todas as bacias catarinenses, a bacia do rio Urussanga, juntamente com a do rio Araranguá, apresenta os piores números, estando classificada em todos os períodos abrangidos como "insustentável". Suas demandas por água, em quantidade e qualidade, estão indicadas na Figura 4, a seguir, com valores que sugerem a urgente necessidade de contínuas intervenções de gerenciamento, acompanhadas de grandes investimentos (Santa Catarina 2018).

Figura 4. Evolução do balanço hídrico na 10a Região Hidrográfica de SC.

\begin{tabular}{|c|c|}
\hline 5 a $10 \%$ - Confortável: & $\begin{array}{l}\text { Pode ocorrer necessidade de gerenciamento para } \\
\text { soluçăo de problemas locais đe abastecimento. }\end{array}$ \\
\hline 10 a $20 \%$ - Preocupante: & $\begin{array}{l}\text { A atividade de gerenciamento é indispensável, } \\
\text { exigindo a realizaçāo de irvestimentos médios. }\end{array}$ \\
\hline 20 a $40 \%$ - Crítico: & $\begin{array}{l}\text { Exige intensa atividade de gerenciamento e grandes } \\
\text { investimentos. }\end{array}$ \\
\hline 40 a $100 \%$ - Muito crítico: & $\begin{array}{l}\text { Exige intensa atividade de gerenciamento e grandes } \\
\text { investimentos. }\end{array}$ \\
\hline$>100 \%$ - Insustentável: & $\begin{array}{l}\text { Exige intensa atividade de gerenciamento e grandes } \\
\text { investimentos urgentes. }\end{array}$ \\
\hline
\end{tabular}

\begin{tabular}{|c|c|c|c|c|c|c|}
\hline \multirow{2}{*}{$\begin{array}{c}\text { Região } \\
\text { Hidrográfica }\end{array}$} & \multicolumn{3}{|c|}{ Quantitativo } & \multicolumn{3}{c|}{ Qualitativo } \\
\cline { 2 - 7 } & 2019 & 2023 & 2027 & 2019 & 2023 & 2027 \\
\hline RH1 & $24 \%$ & $30 \%$ & $39 \%$ & $279 \%$ & $297 \%$ & $303 \%$ \\
\hline RH2 & $14 \%$ & $21 \%$ & $33 \%$ & $200 \%$ & $202 \%$ & $205 \%$ \\
\hline RH3 & $23 \%$ & $36 \%$ & $63 \%$ & $44 \%$ & $45 \%$ & $45 \%$ \\
\hline RH4 & $7 \%$ & $9 \%$ & $14 \%$ & $180 \%$ & $187 \%$ & $194 \%$ \\
\hline RH5 & $14 \%$ & $27 \%$ & $65 \%$ & $55 \%$ & $58 \%$ & $62 \%$ \\
\hline RH6 & $40 \%$ & $47 \%$ & $59 \%$ & $110 \%$ & $115 \%$ & $114 \%$ \\
\hline RH7 & $35 \%$ & $44 \%$ & $58 \%$ & $222 \%$ & $236 \%$ & $244 \%$ \\
\hline RH8 & $28 \%$ & $37 \%$ & $59 \%$ & $270 \%$ & $288 \%$ & $294 \%$ \\
\hline RH9 & $24 \%$ & $31 \%$ & $49 \%$ & $228 \%$ & $251 \%$ & $278 \%$ \\
\hline RH10 & $164 \%$ & $173 \%$ & $204 \%$ & $437 \%$ & $487 \%$ & $536 \%$ \\
\hline
\end{tabular}

Fonte: Santa Catarina (2018).

O prognóstico com números tão negativos é reflexo das atividades econômicas predatórias, que ao longo do tempo foram se diversificando no território da bacia, em combinação com os usos inadequados do solo (desmatamento, ocupação de APPs por atividades várias, como agricultura e mineração). Intervenções que provocaram processos erosivos, com consequente carreamento 
de sedimentos e assoreamento dos rios, além da contaminação por cargas químicas, ilustrada na Figura 5, e orgânicas dos lançamentos industriais e de esgoto doméstico.

Figura 5. Fluxo de água ácida drenando para o rio Carvão, um dos principais afluentes do rio Urussanga.

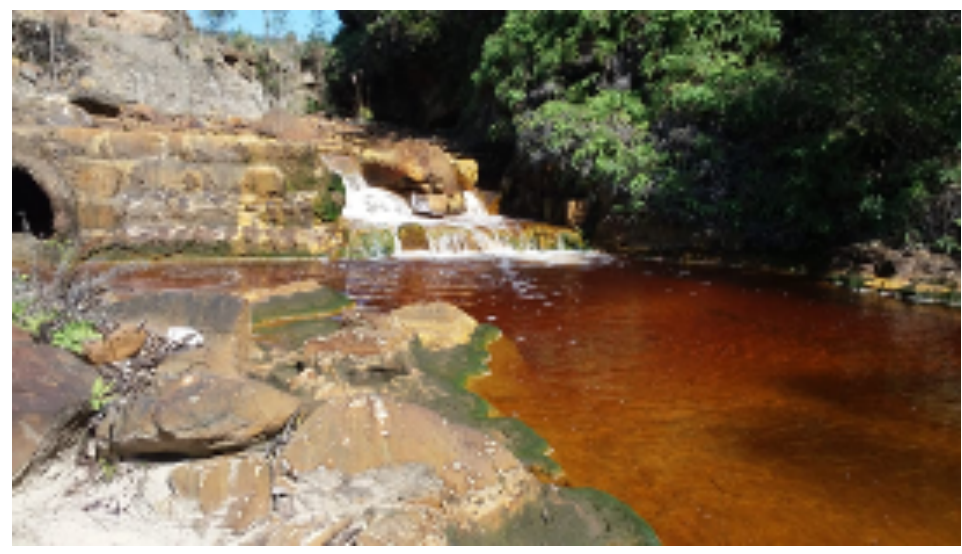

Fonte: Mazzucco (2018).

Os conflitos pelo uso da água são igualmente componentes desse cenário, com os consequentes impactos socioambientais no território da bacia hidrográfica. Dentre estes, destaca-se a resistência durante muitos anos da comunidade de agricultores na localidade de Santa Cruz e arredores, no município de Içara, conta a abertura de uma mina de carvão, que teve vários desdobramentos negativos. Os temores apresentados pela população afetada de que haveria prejuízos severos aos recursos hídricos foram confirmados, após quase sete anos de extração de carvão, conforme relatos de seus representantes. Poços profundos secaram em função da extração de carvão, não voltando a ter recarga, mesmo em períodos de chuva, afetando cerca de 20 famílias (Schneider et al. 2018).

Em Urussanga, a população de Rio Maior também teve que conviver com reflexos negativos da mineração de diabásio, contabilizando prejuízos em seu patrimônio arquitetônico, como rachaduras em prédios históricos, além da poluição atmosférica e impactação nos recursos hídricos (Nascimento e Bursztyn 2012). Tanto nesse caso como no de Içara, não obstante a resistência popular, houve flexibilização de regramentos legais uma vez que as localidades em conflito estavam inseridas em APPs, favorecendo as atividades econômicas em detrimento do interesse comunitário.

O contexto atual da bacia hidrográfica do rio Urussanga, caracterizado nesse trabalho e resultante das dinâmicas de poder envolvendo os seus atores nos diversos segmentos, indica a falta efetiva de arranjos políticos que configurem uma nova governança para a gestão hídrica local. Por conseguinte, o uso da água, que é um bem comum - de direito de todos e já escassa-, tem ocorrido como se fosse em regime privado, sem observância dos regramentos que disciplinam o seu uso, estabelecidos na PNRH.

\section{As falas de atores dos segmentos econômico, político e sociedade civil}

O que pensam alguns atores representantes dos segmentos econômico, político e da sociedade civil acerca da situação da água na bacia hidrográfica do rio Urussanga? Esse aspecto é importante para compreender o atual estágio da gestão hídrica no território estudado, reforçando outros 
elementos levantados na pesquisa, a partir da realização de entrevista semiestruturada, cuja os aspectos mais relevantes são apresentados a seguir, de forma sintética.

Os representantes do setor econômico demonstraram conhecimento superficial sobre o quadro hídrica local, reconhecendo o problema de poluição e suas consequências, mas sem qualquer associação às atividades responsáveis pelos impactos ou ao modelo econômico predatório vigente. Da mesma forma, sabem muito pouco sobre o papel do comitê de bacia e a gestão hídrica, a ponto de não identificarem quais são as instâncias de decisão sobre os usos da água. A opinião de um dos entrevistados, referente à definição de usos dos recursos hídricos, ilustra tal contexto: "Sinceramente, eu não sei. A gente sabe que hoje tem a Casan, que cuida da distribuição da água. Coleta a água, é feito um determinado tratamento para consumo humano. Que o custo dessa água está muito caro para a população em geral”.

Por sua vez, os atores políticos informantes com cargos eletivos, a exemplo dos agentes econômicos, pouco ou quase nada sabem das políticas voltadas à gestão hídrica, embora identifiquem o problema da água na região. Têm um conhecimento bastante limitado sobre o papel dos comitês de bacias e igualmente não sabem identificar quem decide sobre os recursos hídricos. Um dos dois entrevistados citou um conflito pelo uso da água em seu município, no qual produtores rurais, em consórcio, restringiram a captação de água de um curso d'água a uma escola municipal próxima ao local. A existência do comitê para a mediação do conflito foi ignorada, por evidente desconhecimento da sua função. Outros conflitos na região, embora existentes, não foram identificados por ambos, deixando transparecer que o tema água não é recorrente na sua agenda.

Incluem-se também no âmbito do segmento político os atores atuantes no Comitê da Bacia Hidrográfica do Rio Urussanga (representantes do setor público, de usuários de água e da população da bacia), pelo fato de o órgão estar vinculado ao Estado, como instrumento de política pública, além dos profissionais que lhe dão suporte técnico. Neste sentido, por estarem diretamente envolvidos com o comitê, esses mostraram-se naturalmente mais familiarizados com o tema.

Todos apontaram a situação da bacia como crítica, pela contaminação dos mananciais, e reconheceram a assimetria de poderes na definição dos usos da água no território, com sobreposição do setor econômico em relação aos demais segmentos. A afirmação de um dos representantes da população da bacia sintetiza tal entendimento: "A questão econômica atua muito forte. Algumas atividades que causam impacto têm um poder econômico muito grande dentro da bacia". O outro representante do mesmo segmento reforça: "a lei do mais forte prevalece neste setor também. O setor cujo poder econômico é maior, acaba sendo mais unido. Fala em nome da questão econômica, eles acabam definindo o que é melhor para eles".

Em relação à sobreposição ao poder econômico, a mineração de carvão foi indicada como uma das atividades recorrentes na bacia, representando igualmente o principal problema referente à contaminação da água superficial e subterrânea por metais pesados. Sobre essa questão, um dos representantes de órgão público relatou: "A gente tem aí uma pressão da indústria, da própria agricultura e, principalmente, a questão das empresas carboníferas, em se tratando do rio Urussanga e até do rio Araranguá, também".

O modelo predatório vigente no território da bacia que continua comprometendo os mananciais hídricos, conforme os entrevistados do segmento acadêmico, aqui inserido no contexto da população da bacia, foi problematizado durante a abordagem. Dentre eles, dois, formados na área de Ciências da Terra, interpretam o processo como decorrente da falta de consciência dos 
empresários para fazer um manejo adequado dos recursos naturais. O outro representante, por sua vez, da área das Ciências Humanas, apontou o aspecto do paradigma econômico fundamentado no neoliberalismo, para analisar o problema, considerando o grau de complexidade dos processos de construção do território. Todos se mostraram críticos, mas ficou evidente a necessidade de articulação interdisciplinar entre os saberes, levando-se em conta os aspectos sócio-filosóficos e políticos, para além dos físicos e hidrológicos, contribuindo para a melhor problematização do fenômeno em questão.

O papel do governo como órgão gestor dos comitês e, consequentemente, responsável pela gestão hídrica nas bacias hidrográficas também foi enfatizado nas entrevistas com os segmentos. Sobre esse tema, praticamente todos os entrevistados apontaram a falta de comprometimento governamental, principalmente por descontinuar o investimento de recursos à manutenção da estrutura administrativa dos comitês de bacia. Um dos representantes do setor de usuários sintetizou o problema: "O comitê está com atividade bem restrita. Muitas pessoas que estão mantendo o comitê vivo, estão trabalhando como voluntárias, digamos assim".

O entendimento dos diversos atores, na maior parte das abordagens, é convergente, no sentido de que há pela frente um grande desafio a ser superado, em relação à efetiva gestão hídrica, capaz de garantir a todos acesso à água em qualidade e quantidade necessárias. Isso implica maior participação da sociedade nessa instância democrática, para que a assimetria nas relações de poder possa ser superada, em benefício da coletividade.

\section{Considerações finais}

A análise dos dados levantados nesse trabalho, tanto na modalidade documental como de campo, contribuiu para a compreensão sobre a atual realidade da bacia hidrográfica do rio Urussanga. Os elementos abordados ajudaram a lançar luz às dinâmicas de apropriação da água no seu território, demonstrando que essas continuam vinculadas à antiga herança cultural, a partir da qual repousa a visão de que a prioridade de uma região é a de se gerar emprego e renda, aleatoriamente a efeitos colaterais indesejáveis. Por esse prisma, constata-se uma teia de relações envolvendo agentes de vários segmentos, ficando patente a transferência do papel de indução do processo em questão aos setores econômicos. Assim prevalecem os interesses eminentemente corporativos, passando ao largo a participação coletiva na definição de prioridades à área, da qual deveria derivar a expressão de um planejamento de uma região.

Arranjos dessa natureza dão ao segmento econômico uma condição privilegiada e assimétrica de poder, colocando-o acima dos demais interesses no âmbito das tomadas de decisão. Reforça esse status a lógica desenvolvimentista, que se vê repetida como um mantra, reproduzida continuamente nos discursos sociais, que acaba consolidando o modelo de desenvolvimento superado, praticamente concedendo ao segmento econômico a prerrogativa de acesso aos recursos hídricos em caráter privado.

A assimetria de poder, com a imposição de interesses econômicos nos processos decisórios sobre a apropriação da água, tem por extensão a fragilização dos dispositivos legais, estabelecidos para defender os interesses coletivos. Como reflexo disso, constatou-se a alteração de leis ou mesmo sua supressão, com efeitos sentidos em âmbito local, onde comunidades mobilizadas contra empreendimentos poluentes foram inibidas, em função de um modelo que continua hegemônico. 
Sua imposição, considerando as implicações socioambientais resultantes, não representa apenas um problema àqueles que lhes oferecem resistência, mas a toda a coletividade. No caso da água, a sua indisponibilidade prejudica a todos.

Levando-se em conta o papel do comitê da bacia hidrográfica do rio Urussanga, que atua na bacia mais poluída de Santa Catarina e uma das mais poluídas do Brasil, seria imperativo que a situação hídrica local, sobretudo considerando as suas principais fontes poluidoras, fosse objeto permanente de discussão e indicativo de intervenções urgentes de solução ou remediação. No entanto, o órgão ainda não está dotado de condições para esse nível de atuação, cuja fragilidade foi identificada na pesquisa, indicando o seu pouco empoderamento político no enfrentamento do problema, considerando a força que os segmentos econômicos, em especial oriundos do setor carbonífero, ainda detêm nas relações de disputas no território.

Por fim, tem-se a convicção de que a superação dos problemas apontados nesse artigo passa pela transformação da atual forma de interação social no tocante aos recursos comuns. É imperativo que novos modelos de desenvolvimento sejam discutidos na coletividade, com a participação efetiva de todos os segmentos. Não há fórmulas mágicas que resolvam as distorções nas práticas sociais, a não ser por meio de interações ensejadas na valorização da diversidade cultural dos diversos atores, no respeito ao meio ambiente e no exercício pleno da democracia. Sob esse ângulo, o uso racional e solidário da água, com a busca participativa de soluções, é o melhor caminho a ser adotado, ante o abismo que se desenha em virtude das práticas predatórias ainda em curso.

Participação dos autores: JCV - concepção do projeto, coleta e análise dos dados, redação do manuscrito. O trabalho resulta da tese de doutorado de JCV; CTBM, VKA - coordenadores do projeto, revisão do manuscrito.

Aprovação ética ou licenças de pesquisa: Comitê de Ética em Pesquisa da Universidade do Extremo Sul catarinense (UNESC) - no de referência 119 - Parecer 2.399.900/2017.

Disponibilidade dos dados: Os dados estão disponíveis em: http://repositorio.unesc.net/handle/1/7072

Fomento: JCv recebeu bolsa do Programa de Bolsas Universitárias de Santa Catarina UNIEDU/Pós-Graduação.

Conflito de Interesses: Os autores declaram não haver conflito de interesses.

\section{Referências}

Adami RM, Cunha YM (orgs.). 2014. Caderno do Educador das bacias hidrográficas dos rios Araranguá e Urussanga. 2 ed. ver. e amp. Blumenau, SC: Fundação Agência de Água do Vale do Rio Itajaí, 140p.

Augusto LGS, Gurgel IGD, Câmara Neto HF, Melo CH. Costa AM. 2012. O contexto global e nacional frente aos desafios do acesso adequado à água para consumo humano. Ciênc. saúde coletiva, 17(6):1511-1522. DOI: https://doi.org/10.1590/ S1413-81232012000600015

Back, AJ. 2009. Hidrologia e Recursos Hídricos. In: Santos R, Citadini-Zanette V. (Coords.). Mineração de carvão, meio ambiente e desenvolvimento sustentável no sul de Santa Catarina: uma abordagem interdisciplinar. Curitiba: Juruá, 2009. p. 41-49.

Butzke L. Impasses na gestão de recursos comuns e da democracia no Brasil: o caso do carvão mineral no sul de Santa Catarina. 2014. Florianópolis, Tese (Doutorado em Sociologia Política) - UFSC.

Bicudo CEM, Tundisi JG, Scheuenstuhl MCB. 2010. Águas do Brasil: análises estratégicas. São Paulo, Instituto Botânica, 224 p. 
Carola CR. 2010. Progresso, tecnologia e insensibilidade socioambiental. In: Carola CR. (Org.). Memória e cultura do carvão em Santa Catarina: Impactos sociais e ambientais. Santa Cruz do Sul: EdiUNESC. p. 170-195.

Casan. Companhia Catarinense de Águas e Saneamento. 2006. Barragem do Rio São Bento: Água para o Sul de Santa Catarina. Florianópolis: Ed. Coan, 66p.

CBHRU. Comitê de Gerenciamento da Bacia Hidrográfica do Rio Urussanga. 2010. Plano da Bacia do Rio Urussanga: Fase A. Urussanga, Projeto Piava Sul, 121p.

Castilhos ZC, Fernandes FRC. 2011. A bacia carbonífera sul catarinense e os impactos e passivos da atividade da indústria extrativa mineral de carvão na territorialidade. In: Recursos minerais \& sustentabilidade territorial. Grandes minas. Rio de Janeiro: CETEM/MCTI, 1:361-386.

Cazella AA, Bonnal P, MALUF RS. 2009. Multifuncionalidade da agricultura familiar no Brasil e o enfoque da pesquisa. In: Cazella AA, Bonnal P, Maluf RS. (Orgs.). Agricultura familiar: multifuncionalidade e desenvolvimento territorial no Brasil. Rio de Janeiro: Mauad X, p. 47-70.

Corrêa, J. 2004. Atividade minerária no sul de Santa Catarina: Impactos ambientais decorrentes da exploração do carvão. Revista de Direitos Difusos: ADCOAS/APRODAB/IBAP, São Paulo, 25: 3507-3522.

Dowbor L. 2005. Economia da água. In: DOWBOR L., TAGNIN RA. (orgs.). Administrando a água como se fosse importante: gestão ambiental e sustentabilidade. São Paulo: SENAC/SP, 290p.

Echevenguá A. 2010. Carvão e poluição de coquerias: A coisa tá preta em Urussanga-SC. Disponível em: http:// sendosustentavel.blogspot.com/2010/05/carvao-e-poluicao-de-coquerias-coisa-ta.html. Acesso em: 10 dez 2018.

FAPESC - Fundação de Apoio à Pesquisa Científica e Tecnológica do Estado de Santa Catarina. 2010. Autoridades se reúnem em Criciúma para valorizar carvão limpo. Portal Fapesc. Florianópolis,15 set. Disponível em: <http:// www.fapesc.sc.gov.br/2404-autoridades-se-reunem-em-criciuma-para-valorizar-carvao-limpo/>. Acesso em: 3 dez. 2020.

Galatto SL, Simão G, Pereira JL, Alexandre NZ. 2015. Melhoramento fluvial do rio Urussanga pertencente à bacia hidrográfica do rio Urussanga, Sul de Santa Catarina. In: Anais do 15 Congresso Brasileiro de Geologia de Engenharia e Ambiental. Bento Gonçalves.

Getirana, A. 2016. Extreme water deficit in Brazil detected from space. J. Hydrometeorol. 17:591-599. DOI: https://doi. org/10.1175/JHM-D-15-0096.1

Jacobi PR, Cibim J, Leão RS. 2015. Crise hídrica na Macrometrópole Paulista e respostas da sociedade civil. Estud. av., online, 29(84):27-42. DOI: 10.1590/S0103-40142015000200003

Jacobi PR, Empinotti VL, Schmidt L. 2015. Escassez Hídrica e Direitos Humanos. Revista Ambient. soc., online, 19, São Paulo jan./mar. DOI: https://doi.org/10.1590/1809-4422asoceditorialv1912016

Jacobi PR, Grandisoli E. 2017. Água e sustentabilidade: desafios, perspectivas e soluções. São Paulo: IEE-USP/ Reconnecta.

Hess C, Ostrom E. 2007. A Framework for Analyzing the Knowledge Commons. In: Hess, C., Ostrom E. (org.). Understanding Knowledge as a Commons: From Theory to Practice. MIT Press, p. 41-82.

Matsuki E, Sinimbú F. 2018. Reviravolta no mapa da seca: Crises hídricas em SP e no DF mostram que falta d'água não está restrita ao Nordeste. São Paulo: Agência Brasil. Disponível em: http://conteudo.ebc.com.br/portal/projetos/2018/ especiais-agua/reviravolta-no-mapa-da-seca/. Acesso em: 9 abr 2018.

Mazzucco CM. 2018. Registro das condições do rio Carvão (form. digital).

Marques L. 2016. Capitalismo e colapso ambiental. 2 ed. Campinas: Ed. Unicamp, 712p. 
Marques L. 2017. A mercantilização da água avança 'pari passu' com sua escassez. Jornal da Unicamp. Campinas. Disponível em: https://www.unicamp.br/unicamp/ju/artigos/luiz-marques/mercantilizacao-da-agua-avanca-paripassu-com-sua-escassez. Acesso em: 2 fev 2018.

Melo MM. de. 2006. Capitalismo versus sustentabilidade: o desafio de uma nova consciência. Florianópolis: Ed. da UFSC, 134p.

Milioli G. 2009. A indústria de mineração de carvão no Brasil - Ideias para o futuro: o caso de Santa Catarina: In: Milioli et al. Mineração de carvão, meio ambiente e desenvolvimento sustentável no Sul de Santa Catarina: uma abordagem interdisciplinar. Curitiba: Juruá, p. 275-302.

Moretti R. 2010. Rio Carvão cada vez mais poluído. Art. 23. Portal Siderópolis. Disponível em: https://radiosidera. wordpress.com/2010/05/22/rio-carvao-cada-vez-mais-poluido-art-23/. Acesso em: 19 dez 2018.

Nascimento DT, Bursztyn MAA. 2012. Análise de conflitos socioambientais: o caso da comunidade rural de Rio Maior, município de Urussanga, Santa Catarina. R. Inter. Interdisc. INTERthesis, Florianópolis, 9(2):157-190.

Nascimento DT, Bursztyn MAA. 2010. Análise de conflitos socioambientais: atividades minerárias. Desenvolvimento e Meio Ambiente, Curitiba, 22:65-82.

Oakerson RJ. 1992. Analyzing the Commons: a framework. In: Bromley DW et al. Making the Commons Work: theory, practice and policy. San Francisco: ICS Press, p. 41-59.

OMS - Organização Mundial da Saúde, UNICEF - Fundo Internacional de Emergência das Nações Unidas para a Infância. 2017. Progressos em água potável, saneamento e higiene: atualização dos indicadores de referência dos ODS de 2017. Genebra: Organização Mundial da Saúde e Fundo Internacional de Emergência das Nações Unidas para a Infância (UNICEF), 2017, 112P. Disponível em: <https://apps.who.int/iris/handle/10665/258617>. Acesso em: 2 mar. 2018.

Porto MF, Porto PS. de S. 2017. Ecologia política da água: conflitos ambientais no brasil e a defesa dos comuns. In: Jacobi et al.. (Orgs.). Governança da Água no Contexto da Escassez Hídrica. São Paulo: IEE-USP, UFABC e GovAmb, p.114146.

Quivy R, Campenhoudt, L. 1992. Manual de Investigação em Ciências Sociais. Lisboa: Gradiva, 282p.

Santa Catarina. 2018. Plano Estadual de Recursos Hídricos. Diretoria de Recursos Hídricos - Secretaria de Desenvolvimento Econômico Sustentável (SDS). Florianópolis.

Santos T, Santos JV. 2010. Um olhar socioambiental sobre os impactos que a mineração do carvão causa em nossas vidas. In: Carola CR. (Org.). Memória e cultura do carvão em Santa Catarina: Impactos sociais e ambientais. Santa Cruz do Sul: EdiUNESC. p. 170-195.

Scheibe LF. 2002. O Carvão de Santa Catarina: Mineração e consequências ambientais. In: Teixeira, E, Pires MJR. (Coord.). Meio Ambiente e Carvão: Impactos da Exploração e Utilização. Porto Alegre: PADCT/GTM, p. 45-63.

Schneider MS, Martins MC, Virtuoso JC. 2018. Governança da Água na Bacia Hidrográfica do Rio Urussanga: Estudo sobre o Conflito Socioambiental entre Agricultores e Mineração de Carvão na Localidade de Santa Cruz, Içara, SC. In: Anais da IX Semana de Ciência e Tecnologia da Unesc, p. 133-140. Disponível em: http://periodicos.unesc.net/ cienciaetecnologia/article/view/5148/4703. Acesso em: 20 fev 2019.

Silva GS, Garcia R. 2005. Fatores de Competitividade na Indústria de Revestimentos Cerâmicos: uma análise integrada dos sistemas locais de Criciúma (SC) e Santa Gertrudes (SP). In Anais do XXV Encontro Nac. de Eng. de Produção. Porto Alegre. Disponível em: http://www.abepro.org.br/biblioteca/ enegep2005_enegep0704_0120.pdf. Acesso em: 23 nov 2018.

Teixeira JP. 1996. Os donos da cidade. Florianópolis: Insular, 241p. 
Tundisi JG, Tundisi TM. 2015. As múltiplas dimensões da crise hídrica. Revista da USP: Dossiê crise hídrica, São Paulo, 1(106):21-30. DOI: https://doi.org/10.11606/issn.2316-9036.v0i106p21-30 